\title{
Matted Lymph Nodes
}

National Cancer Institute

\section{Source}

National Cancer Institute. Matted Lymph Nodes. NCI Thesaurus. Code C48599.

Lymph nodes adherent to each other, usually a result of tumor spread. 